DOI 10.5216/ia.v46i3.68464

\title{
"MEU MAIOR SONHO É SER REI DA BATERIA DO CAMISA": VOZES DAS INFÂNCIAS NA ESCOLA DE SAMBA
}

\author{
RoBerta CRISTINA de PAULA \\ Prefeitura Municipal de Campinas (PMC), Campinas, São Paulo, Brasil \\ PatrícIa Dias Prado \\ Universidade de São Paulo (USP), São Paulo, Brasil
}

\begin{abstract}
Resumo: Este artigo apresenta o percurso metodológico da pesquisa etnográfica realizada junto à Ala das Crianças de uma Escola de Samba paulistana, com objetivos de conhecer as vivências de meninas e meninos a partir desse lócus, destacar aspectos relacionados às categorias de sexo/gênero, idade/geração, raça/etnia, e ampliar a compreensão sobre as pluralidades das infâncias negras brasileiras. $O$ estudo estruturou-se nos seguintes instrumentos metodológicos: observação participante, conversas informais, com registros em caderno de campo e a realização de entrevistas semiestruturadas, com roteiros prévios e mediante autorização. As análises revelam a Escola de Samba como espaço de reprodução de valores e padrões de uma sociedade branca, mas também, território e terreiro de criações de outras narrativas sobre as infâncias de meninas e meninos negras/os que para além do preconceito e da discriminação racial, questões abordadas na maioria das produções acadêmicas sobre esta temática no campo educacional, revelam sonhos e possibilidades de se tornarem reis e rainhas, de identidade negra potente e de pertencimento.
\end{abstract}

Palavras-chave: Crianças Negras. Educação. Identidades. Escola de Samba.

INTRODUÇÃO: SOBRE O ENREDO E A COMISSÃO DE FRENTE

\begin{abstract}
Batuque é um privilégio, ninguém aprende samba no colégio, sambar é chorar de alegria, é sorrir de nostalgia, dentro da melodia'.
\end{abstract}

(ROSA; GOGLIANO, 1933)

Para a elaboração deste artigo, destaca-se o percurso metodológico de pesquisa de doutorado (PAULA, 2019) apresentando os/as colaboradores/as que compõem a Ala das Crianças de uma Escola de Samba paulistana, trazendo suas "vozes" e suas vivências, além de aspectos relacionados às categorias de sexo/gênero, idade/geração, raça/etnia, apontando elementos concretos e simbólicos para a constituição das identidades negras das crianças, observados no contexto em questão.

Para o desenvolvimento do referido estudo, assim como deste artigo, buscou-se inspiração nos quesitos que são avaliados em um desfile de Carnaval de uma Escola de Samba. Nilza de Oliveira (1996) explica que foi a partir da pergunta-chave da sua pesquisa: "o que é uma Escola de Samba?" que nasceu o livro Quaesitu, termo esse que 
corresponde a quesito. Ao relacionar a ideia de quesito à pesquisa, o objeto da investigação foi chamado de Enredo, sendo o fio condutor desta empreitada que propõe a intersecção entre infâncias, Escola de Samba, educação e identidades negras, daí suscitando a seguinte interrogação: quais os conhecimentos e saberes produzidos e reproduzidos por meninos e meninas da Ala das Crianças da Escola de Samba em questão, que se mostram como elementos concretos e simbólicos no processo de construção das identidades negras?

Apresentado o Enredo, inicia-se a montagem da Escola (pesquisa), com a Comissão de Frente, sendo essa a Ala que vai à frente de uma Escola de Samba. Neste estudo, a Comissão de Frente é as infâncias na Escola de Samba, escolha feita como resultado das trajetórias pessoal, profissional e acadêmica das pesquisadoras que reúnem questões ligadas à constituição de suas identidades de raça, de gênero e outras relacionadas às suas atuações como professoras e pesquisadoras das infâncias, além de experiências no campo das culturas populares, em destaque, para as danças e ritmos brasileiros.

Partindo de reflexões advindas desses percursos, procurou-se analisar as infâncias de meninos e meninas em um espaço educacional não escolar, originário das culturas negras, uma vez que, segundo Muniz Sodré (1979, p. 41), "[...] o samba é ao mesmo tempo um movimento de continuidade e afirmação de valores culturais negros".

Com isso, faz-se aqui o convite para conhecermos outras infâncias, reconhecendo as crianças negras e a Educação para além da escola formal, pois, no decorrer de décadas, foram enfatizados os conhecimentos disseminados nos espaços escolares.

Jens Qvortrup (2010) diz que a infância é o resultado das fortes relações entre os parâmetros econômicos, políticos, sociais, culturais, tecnológicos, ideológicos e/ou discursivos que prevalecem em uma sociedade, os quais devem ser considerados como forças estruturais:

[...] a infância enquanto espaço social no qual as crianças vivem, transforma-se constantemente, da mesma forma que a idade adulta e a velhice também se modificam. Essas transformações não podem esconder, no entanto, a contínua existência e realidade da infância enquanto categoria estrutural. Em termos estruturais, portanto, ela não é transitória e não é um período; tem permanência. $O$ desenvolvimento histórico da infância não acaba com a sua categoria; e a variabilidade cultural da infância contemporânea testemunha a favor da sua presença universal (QVORTRUP, 2010, p. 637, grifos do autor).

Dessa forma, ao trazer esse conceito, apresentamos como infâncias no plural, pois são múltiplas, variando de acordo com os diferentes grupos sociais e demais categorias, como sexo/gênero, raça/etnia, idade/geração. Mais recentemente, no último quarto do século XX, nas pesquisas das áreas das Ciências Sociais e Humanas, a categoria infância também vem sendo empregada de forma a dar visibilidade às pluralidades das infâncias e a trazer as "vozes" das crianças, diferenciando-se, assim, de uma perspectiva 
PAULA, R. C. de; PRADO, P. D.

de infância no singular, concebida somente enquanto uma fase preparatória para a vida adulta, reforçando um caráter transitório.

Paralelamente a essa nova postura frente aos Estudos da Infância, a concepção de que as crianças são produtoras de culturas, afirmada desde Florestan Fernandes (2004), inaugura o protagonismo de meninas e meninos como agentes que constroem história, transformam as relações e a sociedade:

\begin{abstract}
Concebo as culturas infantis como mediação (FERNANDES, 1979), que não se dá somente em obras materiais, mas também na capacidade de as crianças transformarem a natureza e de estabelecerem relações sociais múltiplas e diversas, já que se constituem a partir das diferentes experiências de todos os atores sociais presentes no contexto educativo e na sociedade mais ampla, em relação. As culturas infantis manifestam-se como aberturas para novas formas de ver e compreender a infância e seu significado, tanto para as próprias crianças como para além delas (PRADO, 2015, p. 16).
\end{abstract}

Com isso, o emprego do termo culturas infantis no plural considera que, assim como as infâncias, as culturas também são múltiplas, uma vez que outras categorias são levadas em consideração. Conforme Fabiana Canavieira e Ana Cláudia Caldeiron (2011), são muitas as infâncias e diversas são as formas que elas podem ser vividas dentro de um mesmo tempo histórico e espaço geográfico.

\title{
O PERCURSO METODOLÓGICO: EM BUSCA DA HARMONIA
}

\begin{abstract}
Na sua bandeira, enxuguei o pranto de uma dor não esquecida, deslumbrante na avenida, a minha escola é realmente a mais querida ${ }^{2}$.
\end{abstract}

O percurso metodológico é aqui denominado como a Harmonia, quesito que mede se o desfile foi bom ou não, pois, ao fazer a escolha por um método, pretende-se com ele trilhar uma trajetória que desembocará em possíveis respostas para a elucidação do objeto em questão, tornando-se imprescindível a articulação entre metodologia e epistemologia.

A pesquisa de campo iniciou-se em março de 2016, finalizando em março de 2018. O modo escolhido foi a etnografia, na busca por conhecer as infâncias de meninos e meninas da Ala das Crianças de uma Escola de Samba Paulistana; trazer as "vozes" das crianças que, segundo Prado (1999), referem-se a várias formas de expressão, como gestos, sorrisos, olhares, choros, silêncios, linguagens sonoras e outras linguagens; e problematizar o papel da Escola de Samba no processo de educação e de construção das identidades negras pelas meninas e pelos meninos. Para esta investigação, reportamo-nos aos campos teóricos da Pedagogia da Infância e das Ciências Sociais, em que se destacam a Antropologia e os Estudos Sociais da Infância, sendo que:

O reconhecimento de outro estatuto às crianças como atores sociais tem radicado na defesa de uma agenda de pesquisa que, entre 
outras premissas, vê no uso da etnografia um contributo inestimável ao debate epistemológico, teórico-metodológico e ético em curso nas múltiplas disciplinas das ciências sociais integrantes dos estudos da infância (FERREIRA; NUNES, 2014, p. 106).

Entre os/as interlocutores/as teóricos ressaltamos: Da Matta (1978), Sodré (1979), Ludke; André (2013), Oliveira (2000), Faria; Demartini; Prado (2009), Fernandes (2004), Hall (2004), Simson (2007), Finco (2008), Gomes (2005), e Baronetti (2015). Também foram referências para nós as pesquisas etnográficas já realizadas com crianças negras, dentre elas: Souza (2015), Nunes (2017) e Souza (2016), tendo, respectivamente, como campos de investigação um quilombo, uma Escola de Educação Infantil situada dentro do bloco afro Malê Debalê e um terreiro de Candomblé.

Os procedimentos para produção dos materiais de pesquisa foram a observação participante, conversas informais com registros em caderno de campo e entrevistas semiestruturadas, feitas com as crianças e seus familiares com autorização e roteiro prévios, e também com a Coordenadora e uma Apoio da Ala das Crianças. A função de Apoio nessa Ala, historicamente, segundo informações colhidas era ocupada por mulheres, por isso o uso do feminino. Especificamente, em se tratando da metodologia de pesquisa realizada com as crianças, destacamos a importância que foi a possibilidade de atuação por meio da observação participante, fator que contribuiu potencialmente para a aproximação junto às meninas e meninos, para além das entrevistas.

Um dos aspectos priorizados nesse processo foi a obtenção do consentimento das crianças para a entrada da pesquisadora no grupo. Registra-se que foi em um dos ensaios da Ala, que acontecia aos domingos à tarde, que a Coordenadora da Ala chamou a pesquisadora ao centro da roda e explicou para as meninas e meninos o que ela estava querendo ali: "conhecer o que faziam".

Em seu artigo "Pesquisa Etnográfica com Crianças: participação, voz e ética", Rita de Cássia Marchi (2018) ressalta a importância de informarmos às crianças sobre a pesquisa, pois a ética inclui em falarmos das nossas intenções naquele espaço. $O$ problema do ponto de vista ético, constitui-se quando o pesquisador não se apresenta como tal às crianças e nem as informa sobre a pesquisa.

As entrevistas, por sua vez, deram-se oficialmente com o consentimento de familiares responsáveis pelas crianças, mas também considerando a receptividade das meninas e meninos ao convite para participarem dessa proposta, e respeitando suas falas, silêncios e diferentes tempos. Isto é, algumas crianças demonstraram maior disposição para desdobramentos das questões apresentadas, enquanto outras expressaram menos abertura para um aprofundamento das conversas.

Os dois anos de pesquisa de campo incluíram desde os contatos prévios, via WhatsApp e Facebook para a definição da agremiação, que possibilitaria a realização da pesquisa; os primeiros encontros com a Coordenadora da Ala das Crianças, com parte do grupo de meninas e meninos da Escola investigada, paralelamente a apresentação ao presidente da agremiação que autorizou o desenvolvimento do estudo. A partir dessas incursões iniciais, deram-se diversas outras ações que permitiram a imersão em experiências no espaço da Escola e fora dele, as quais tiveram como foco a construção 
PAULA, R. C. de $;$ PRADO, P. D.

de vínculos com as crianças e seus familiares, entre elas: o compartilhamento de festas e ensaios na quadra, complementado com atividades em espaços externos, como eventos em quadras de outras Escolas de Samba, visitas ao barracão da Escola investigada, Piqueniques da Ala das Crianças, ensaios de rua, ensaios técnicos, desfile oficial etc.

A busca pela participação em diferentes atividades foi por entendermos que o conhecimento das culturas do contexto investigado incluía não somente a observação desses momentos, mas também, por meio deles, a construção de relações de trocas com os/as componentes dos diferentes segmentos da Escola, atentando-se às relações hierárquicas de conflito, de poder, de tensão, de solidariedade e de identidades que eram firmadas:

A justificativa para que o pesquisador mantenha um contato estreito e direto com a situação onde os fenômenos ocorrem naturalmente é a de que estes são muito influenciados pelo seu contexto. Sendo assim, as circunstâncias particulares em que um determinado objeto se insere são as essenciais para que se possa entendê-lo. Da mesma maneira, as pessoas, os gestos, as palavras estudadas devem ser sempre referenciadas ao contexto onde aparecem (LUDKE; ANDRÉ, 2013, p. 12).

A ALA DAS CRIANÇAS: A "BATERIA"

Todo menino é um rei, eu também já fui rei, mas quá! Despertei! ${ }^{3}$

A Ala das Crianças representa aqui o nosso "coração pulsante" que, na Escola de Samba é representado pela Ala da Bateria; focando nos meninos e nas meninas como colaboradores/as, atores sociais nessa investigação, o desafio foi trazer as suas "vozes" para o centro. Conforme Marchi (2018), foi a partir de 1989, com a proclamação da Convenção sobre os Direitos da Criança que, pela primeira vez, é garantida às crianças o direito de participação e voz nos assuntos que lhes afetam. "Se no texto da Convenção esses direitos estão relacionados a processos judiciais e administrativos que dizem respeito à criança, eles foram rapidamente também levados em conta nas pesquisas" (MARCHI, 2018, p. 733).

Ainda sobre esse aspecto, Manuela Ferreira e Ângela Nunes (2014, p. 117) alertam: "Ao que tudo indica, as crianças passaram a "falar" como sujeitos participantes, mas revelar e tornar essas vozes audíveis através dos textos etnográficos requer uma reflexão mais ampla sobre a sua tradução, interpretação e mediação [...]".

Essa afirmação remete à fórmula apresentada por Roberto Da Matta (1978), atentando-se para o duplo trabalho do/a etnólogo/a, que é a transformação do exótico em familiar e do familiar em exótico, pois: “[...] em ambos os casos, é necessário a presença dos dois termos (que representam dois universos de significação) e, mais basicamente, uma vivência dos dois domínios por um mesmo sujeito disposto a situá-los e apanhá-los" (DA MATTA, 1978, p. 4).

Pesquisas realizadas em instituições educacionais, ao se reportarem às crianças negras, constatam aspectos da discriminação e do preconceito racial que caracterizam 
as relações, ou que estão atrelados a elas, direta ou indiretamente (ROSEMBERG, 1987; CAVALLEIRO, 1998; SOUZA, 2002; SANTIAGO, 2014; FARIAS, 2016).

A utilização do termo negras para referir-se às crianças pretas e pardas está de acordo com Vilma Pinho e Suelen Santos (2014), que afirmam que pardos/as e pretos/as são considerados/as negros/as, sendo que negra não é uma cor, mas uma categoria racial política construída pelo Movimento Negro como forma de resistência à discriminação racial e ao racismo.

Em se tratando da categoria raça/etnia, a investigação aponta que, majoritariamente, a Ala das Crianças é composta por crianças negras. O método de classificação racial empregado foi o da heteroatribuição, quando outras pessoas definem o grupo do sujeito (OSÓRIO, 2003) - nesse caso, isso foi feito por nós pesquisadoras. Além de observações como tom da pele, cabelo e outras características físicas, outro fator que contribuiu para a identificação do grupo em questão foi conhecer seus familiares. Contudo, é necessário registrar que há a participação de crianças nãonegras na agremiação investigada.

Sobre a categoria étnico-racial, em entrevista, a Apoio da Ala das Crianças, Fabiana, mulher negra, de 19 anos, disse quando perguntada sobre a construção do seu pertencimento racial enquanto negra, que a participação em sua Escola de Samba colaborou nesse processo, uma vez que:

-[...] ali a maioria é negra, a maioria, não há como você chegar no Camisa e falar não, a maioria é branca, não, a maioria é negra (Entrevista com Apoio de Ala, 28.04.2016).

Entretanto, ao indagar a Coordenadora da Ala, Bárbara, mulher negra, de 40 anos, sobre o pertencimento étnico-racial dos/as componentes da Ala, disse não se importar com raça, salientando que havia a presença de diferentes crianças, como japonesas, italianas, indígenas. Porém, no período dessa pesquisa não foi observada a presença de crianças pertencentes a esses grupos étnico-raciais na Ala das Crianças.

-Raça, assim é... Eu não caracterizo raça. Eu caracterizo pessoas, seres. Independente de cor de raça, independente de distinção racial... Então, pra mim negro, branco, eu não faço distinção. Independente de ser negro, de ser branco, de ser pardo, estão todos ali, amando, tentando dar o melhor para o Pavilhão ${ }^{4}$. Então, eu acho que não tem muito essa coisa de negro (Entrevista com Bárbara, Coordenadora da Ala, 28.04.2016).

Segundo Nilma Gomes (2005), quando se pergunta sobre raça nem sempre se recebe como resposta uma reação positiva da outra pessoa, pois a forma de reação a essa questão dependerá, principalmente, do entendimento, da leitura e da construção da identidade étnico-racial da pessoa que é questionada.

No que diz respeito à participação das crianças na Escola de Samba pesquisada, observou-se que isso ocorre por meio da Ala das Crianças, da Ala da Bateria ou ainda da Ala dos/as Passistas Mirins. Conforme informação obtida junto à Coordenadora, é na da 
PAULA, R. C. de $;$ PRADO, P. D.

Ala das Crianças que se concentra em torno de $80 \%$ desses meninos e meninas que são componentes da agremiação.

A entrada dessas crianças associa-se, geralmente, ao fato de um/a membro da sua família também ser componente da Escola. As que compõem a Ala das Crianças têm, em sua maioria, vínculos parentais com integrantes de outras Alas.

A faixa etária das meninas e dos meninos que compõem a Ala investigada é dos 7 aos 14 anos, mas a saída do grupo pode ser antecipada no caso delas/es começarem um namoro, aspecto que, segundo a Coordenadora, caracterizaria o "deixar de ser criança".

Entre as atividades vivenciadas, foram nos Piqueniques da Ala, sendo dois durante o ano de 2016 e um no ano de 2017, que foi observado maior espaço e tempo para as brincadeiras coletivas das crianças, como jogo de futebol, vôlei, escondeesconde e outras como: andar de bicicleta, gangorrar, balançar. Em entrevista, João, menino negro, de 10 anos, quando perguntado sobre o tempo do brincar nos Piqueniques e nos ensaios, demonstrou que há diferença, dizendo que:

-Tem tempo, porque a gente brinca bastante. Piquenique é hora da brincadeira, vamos dizer. A gente brinca, come... Já sobre os ensaios, disse: $-A$ gente brinca um pouquinho, depois a tia (Coordenadora da Ala) manda subir, né? Referindo-se ao tempo de espera, quando a Ala fica concentrada no camarote (Entrevista com João, 03.09.2017).

Nesses dias, percebeu-se a possibilidade de meninos e meninas terem escolhas, buscarem seus pares para as brincadeiras favoritas, mas sempre às vistas dos/as adultos/as. Destaca-se que também foram observadas brincadeiras coletivas com a participação de meninos e meninas em um jogo de futebol, com uma rápida divisão feita pelos meninos na formação dos times, em que um deles alegou que poderiam ter uma menina com eles, pois ela jogava bem - nesse dia duas meninas integraram as equipes, uma em cada grupo.

Essa passagem relaciona-se à afirmação de Sayão (2003), quando afirma que parte da bibliografia que tem se dedicado ao tema da infância, institucionalizada ou não, argumenta sobre a relevância da inclusão da categoria de gênero em suas análises, associada à classe, à raça/etnia e a outros aspectos possíveis. Sobre essa tríade, Joan Scott (1995) relembra que o interesse de pesquisadores/as pelas categorias de classe, raça e gênero marcava, no início, o pacto com uma história que incluía as vozes dos/as oprimidos/as e análise sobre o sentido e a natureza da sua opressão. Além disso, "[...] assinalava também que esses/as pesquisadores/as levavam cientificamente em relação ao fato de que as desigualdades de poder estão organizadas segundo, no mínimo, estes três eixos" (SCOTT, 1995, p. 73).

Outros dados observados no decorrer da pesquisa mostraram a emersão da categoria gênero, evidenciando a necessidade de apontar os marcadores presentes no contexto investigado que possibilitam análises relativas às construções das identidades dos meninos e das meninas, sujeitos deste estudo. Para Daniela Finco (2008, p. 1): “A utilização do gênero como categoria de análise implica conhecer, saber mais sobre as diferenças sexuais. Compreender como são produzidas pelas culturas e sociedades nas relações entre homens e mulheres". 
Em se tratando da quadra da Escola, quando aconteciam os ensaios da Ala aos domingos à tarde, no período pré-carnavalesco, de novembro a fevereiro, como mencionado, havia um aumento considerável da frequência de crianças. Após o ensaio da coreografia os meninos e meninas ficavam com um tempo livre para brincarem, o que os/as levava a correr pelo espaço livre, geralmente, brincando de pega-pega ou esconde-esconde e também, conforme dito em entrevista por Rosa (em 03.09.2017), menina negra de 6 anos, brincavam de "futebol de garrafa", isto é, quando a bola era substituída por uma garrafa plástica.

Todavia, esse tempo era restrito em razão do início das rodas de Samba, abertas ao público e que antecediam os ensaios da noite, de modo que o centro da quadra era ocupado por sambistas da Escola, o que impossibilitava a continuidade das brincadeiras.

Dessa forma, a partir desse momento, as crianças eram direcionadas a ocuparem os camarotes ${ }^{5}$, que são espaços delimitados, seja no térreo, seja no mezanino. São as Apoios ${ }^{6}$, juntamente à Coordenadora, que têm a função de cuidar dos meninos e meninas, fazendo com que a circulação deles/as pela quadra fosse controlada. Percebeu-se que era nesse tempo de espera, até o início do ensaio, à noite, que as crianças ficavam mais agitadas por ficarem limitadas a um espaço que oferecia pouca possibilidade de movimentação e, com isso, por vezes, driblavam e subvertiam uma ordem que era imposta: aguardar disciplinarmente a hora do ensaio.

llustrando esse cenário, houve um episódio em que alguns meninos iniciaram uma brincadeira cujo desafio era jogar uma garrafa de $510 \mathrm{ml}$, com aproximadamente $300 \mathrm{ml}$ de líquido, ao centro da roda formada por eles e fazer com que esta caísse na posição vertical, "em pé". Essa brincadeira começou com seis meninos, depois chegaram mais crianças, entre elas duas meninas. A pesquisadora aproximou-se do grupo e pediu para fazer algumas tentativas, mas não obteve sucesso nas suas jogadas. O grupo ficou por volta de 30 minutos motivado com o jogo.

Felizmente, apesar de toda coerção, as crianças brincam em qualquer circunstância, sempre encontram um jeito para se divertir: sozinhos ou em grupo, no trabalho ou nas brechas do gerenciamento do tempo na escola, transgredindo, muitas vezes, aquilo que os adultos tentam impor (FINCO, 2007, p. 97).

Daniela Finco (2008) afirma que os princípios de determinadas práticas pedagógicas se relacionam às técnicas disciplinadoras discutidas por Michel Foucault, explicando que: "Os elementos tempo, espaço e movimento estão intrinsecamente ligados ao controle do corpo como a forma de trabalhá-lo detalhadamente, de exercer sobre ele uma coerção sem folga, de mantê-lo ao mesmo nível da mecânica, disciplina e ao controle do corpo na execução das tarefas" (FINCO, 2008, p. 4). Em entrevista, ao perguntar para João, o que achava do tempo que ficavam no camarote, ele disse:

-Esse eu não sei como responder... A gente fica conversando, né? Fica ouvindo a bateria ensaiar. Dá uma dançadinha, depois desce para ensaiar (Entrevista com João, 03.09.2017). 
PAULA, R. C. de $;$ PRADO, P. D.

No primeiro momento da tarde de domingo, o ensaio da Ala era feito separadamente dos outros segmentos da agremiação. As coreografias dos Sambasenredo caracterizaram-se por movimentos e gestos que se apoiavam na letra da música, chamando a atenção para o fato de não ser privilegiado um espaço/tempo para a vivência da dança do Samba por parte das crianças. Todavia, em uma das entrevistas, ao perguntar ao João sobre a coreografia apresentada pela Ala das Crianças, ele explicou que:

-Ah, é um Samba diferente, vamos dizer... É um Samba com as mãos, com os pés. Esse Samba com essa coreografia é com o corpo todo, e a gente faz, né? Com a cabeça, com a mão... e é bem diferente! (Entrevista com João, 03.09.2017).

Exceto os momentos de ensaios obrigatórios, houve situações em que crianças e adultos/as sambavam sem uma marcação coreográfica. Exemplos disso eram os finais de ensaios nas noites de domingo, quando vários/as componentes e o público em geral, descontraidamente, aglomeravam-se no centro da quadra e dançavam ao som da bateria que ficava tocando por um tempo, aparentemente livre das formalidades que caracterizavam o período de tempo dos ensaios.

Em um episódio ocorrido durante a noite de escolha do Samba-enredo para o Carnaval 2017, junto à Ala das Crianças no camarote, Vitória, mulher negra, de 78 anos, bisavó de João, aproximou-se dele e convidou-o para sambar com ela. Esta foi uma das cenas mais marcantes das experiências vivenciadas em campo. Tal fato suscitou a análise de relações possibilitadas a partir dessa linguagem, fazendo com que sujeitos que, em um primeiro momento, se identificariam como pertencentes a diferentes gerações, mostram-se compartilhando uma mesma experiência (LARROSA, 2002).

Outros momentos que proporcionaram encontros de sujeitos de diferentes idades se deram durante as Festas Junina e Julina, quando se acompanhou a dança da "quadrilha maluca", na qual participaram crianças, jovens, adultos e senhores/as, um acontecimento que promoveu a confraternização entre os/as componentes de várias Alas da Escola. Segundo Alda Britto da Motta (2010):

O sentido mais plenamente sociológico, ou macrossociológico geração, propriamente dita - designa um coletivo de indivíduos que vivem em determinada época ou tempo social, têm aproximadamente a mesma idade e compartilham alguma forma de experiência ou vivência, ou têm a potencialidade para tal (BRITO DA MOTTA, 2010, p. 229).

Em relação a pesquisas sobre a discussão da categoria geracional, evidencia-se a forte demarcação das idades na contemporaneidade, o que tem implicações significativas na dinâmica social, pois: "O significado das diversas idades, no entanto, constrói-se e reconstrói-se de modo permanente no interior de uma mesma sociedade" (PRADO, 2015, p. 27).

Ainda ao que se refere à dança, na entrevista com Paulo, menino de 10 anos, negro, até então componente da Ala das Crianças, disse que a partir daquele dia passaria a compor a Ala de Passistas Mirins. Nessa entrevista ele expressou a sua paixão pelo 
mundo do Samba e do Carnaval, que estava nessa Escola de Samba desde os 6 meses e que quem teve a iniciativa de levá-lo para a Escola foi a sua madrinha. Paulo desfilou pela primeira vez aos 6 anos de idade e um dos seus objetivos era integrar a Ala de Passistas Mirins. Quando perguntado a ele: "Qual é o seu maior sonho?", ele respondeu: que era ser "Rei da Bateria do Camisa" (Entrevista com Paulo, 19.12.2016).

Diante dessa afirmação, indagou-se sobre a existência de Rei de Bateria e Paulo explicou que já conhecera um em outra Escola de Samba. Notam-se, com esse relato, as transformações que vêm ocorrendo e alterando as formas de se caracterizar algumas funções sem a flexão de gênero, pois esse papel, tradicionalmente, era ocupado somente por mulheres, sendo elas as Rainhas de Bateria.

[...] as crianças lidam com modos de viver as relações de gênero que Ihes são dados a priori e os recriam de maneira particular, em parte reproduzindo, em parte transformando, vivenciando à sua maneira esse movimento de manter e recriar, que é do conjunto da sociedade (CRUZ; CARVALHO, 2006, p. 143).

Por sua vez, a colaboradora Manuela, ao responder a mesma questão, disse: "- $O$ meu maior sonho é que eu esteja na Ala das Baterias para tocar tambor" (Entrevista com Manuela, em 24/03/2018, menina de 7 anos, negra). Percebeu-se que, além dela, outras meninas e mulheres desejam atuar, ou já atuam nesse segmento da Escola que, historicamente, nas agremiações foi composto por homens.

\title{
ANÁLISES E REFLEXÕES PARA A COMPOSIÇÃO DO SAMBA-ENREDO
}

\begin{abstract}
O samba ainda vai nascer, o samba ainda não chegou, o samba não vai morrer, veja o dia ainda não raiou. $O$ samba é o pai do prazer, o samba é o filho da dor, o grande poder transformador?.
\end{abstract}

(VELOSO, 1993).

O Samba-enredo se refere às nossas considerações elaboradas ao final desse processo, assim, reconhecemos que o fazer etnográfico tem o poder de nos colocar frente a frente com nós mesmos/as, com isso deparamo-nos com situações que também proporcionaram o reconhecimento de elementos concretos e simbólicos que possibilitaram a construção de nossas identidades negras.

O antropólogo Kabengele Munanga (2009) reforça que, para as mulheres e os homens - e acrescentamos as crianças - descendentes de africanas/os no Brasil e no mundo, a revalorização e a aceitação da sua herança africana se inserem em um processo de reconstrução da identidade coletiva. A negritude constitui uma luta para a reconstrução positiva de sua identidade sendo, portanto, um tema da atualidade.

A busca por outras infâncias no espaço da Escola de Samba remete à trajetória das pesquisadoras que encontraram nas danças populares um espaço de 
PAULA, R. C. de; PRADO, P. D.

reconhecimento de culturas, até então desconhecidas e, consequentemente, desvalorizadas em outros ambientes sociais. Sodré (1979) afirma que:

Sendo um discurso tático de resistência no interior do campo
ideológico do modo de produção dominante - perpassado por
ambiguidades, avanços e recuos, característicos de todo discurso
dessa ordem - o samba é ao mesmo tempo um movimento de
continuidade e afirmação de valores culturais negros (SODRÉ, 1979,
p. 41).

Diante desse cenário, a Escola de Samba, também na atualidade, tem potencialidades para ser um terreiro ${ }^{8}$ de criações culturais de resistência. Conforme Simson (2007), desde a época colonial até os nossos dias atuais, os agrupamentos negros atuam no campo da cultura para preencherem as carências surgidas na diáspora.

Observou-se que, como em outros espaços educacionais, os interesses das crianças, também nessa Escola, foram por vezes desconsiderados em razão da supremacia dos interesses dos/as adultos/as tendo, assim, seus espaços, tempos e brincadeiras limitados em prol de outros objetivos, mostrou-se aspectos da incompatibilidade entre as vivências das culturas do Samba e das infâncias.

Na busca pelo reconhecimento das culturas infantis, o campo traz à tona novos elementos, implicando a dupla tarefa indicada por Da Matta (1978): estranhar e familiarizar-se. É nesse exercício que se procurou conhecer essas infâncias de meninos e meninas, registrar suas "vozes" e analisar o papel da Escola de Samba no processo de sua educação e da construção das identidades negras.

Entretanto, concebendo o conceito de identidades como um processo constante de construção e transformação (HALL, 2004), constituído na e pelas relações sociais (GOMES, 2005), destaca-se a participação das crianças como produtoras de sentidos e significados.

Com isso, as "vozes" dos meninos e das meninas negros/as mostram que a Escola de Samba investigada vem se caracterizando como um espaço cultural, de lazer, de Educação, de pertencimento, de construção potente de identidades e de infâncias, mesmo diante das contradições e conflitos também inerentes a ela. Um espaço simbólico e representativo da festa, de celebração da vida, de criação e transgressão!

"Meu maior sonho é ser rei da bateria do Camisa!" (Paulo, 19.12.2016).

Artigo recebido em: 01/04/2021

Aprovado para publicação em: 03/11/2021

"MY BIGGEST DREAM IS TO BE THE KING OF CAMISA'S DRUMS!": CHILDHOOD'S VOICES AT SAMBA SCHOOL

ABSTRACT: This article presents the methodological and ethnographic research, which was made with the "Ala das Crianças" of a Samba School in São Paulo, with the purpose of knowing the experiences of girls and boys from this locus, the highlighting and the aspects related to the 
categories of sex/gender, age/generation, race/ethnicity, and expanding the understanding of the pluralities of Brazilian black children. The study was structured in the following methodological instruments: participant observation, informal conversations, with records in a specific notebook and semi-structured interviews, with previous scripts and their authorization. The analyses reveal the Samba School as a space for the reproduction of values and patterns of a white society, but also, a territory of creations of other narratives about the childhoods of black girls and boys/ those who, in addition to prejudice and racial discrimination, such issues are addressed in most academic research on this theme in the educational field, and reveal dreams and possibilities to become kings and queens, of powerful black identity and belonging.

KEYWORDS: Black Children. Education. Identities. Samba School.

\section{"MI MAYOR SUEÑO ES SER REY DE LA BATERIA DEL CAMISA!": VOCES DE LAS INFANCIAS EN LA ESCUELA DE SAMBA}

RESUMEN: Este artículo presenta el percurso metodológico de la investigación etnográfica realizada en el Ala de las/os Ninãs/os de una Escuela de Samba paulistana, con objetivos de conocer las experiências de niñas y niños a partir de ese lugar; destacar aspectos relacionados a las categorias de sexo/gênero, edad/generación, raza/etnia, y ampliar la comprensión sobre las pluralidades de las infancias negras brasileñas. El estudio estructurose en los siguientes instrumentos metodológicos: observación participante, conversaciones informales, con registros en cuaderno de campo, y la realización de entrevistas semiestructuradas. El análisis revela la Escuela de Samba como espacio de reprodución de valores y normas de una sociedad blanca, pero también território y terreiro de creaciones de otras narrativas sobre las infancias de niñas y niños negras/os que, para más allá del prejuicio y de la discriminación racial, problemas abordados en la mayoría de las producciones acadêmicas sobre la temática en el campo educativo, revelan sueños y posibilidades de convertirse reyes y reinas, de identidad negra poderosa y de pertenecimiento.

PALABRAS CLAVE: Niñas/os Negras/os. Educación. Identidades. Escuela de Samba.

\section{NOTAS}

1 - Trecho da letra da música "Feitio de oração", de 1933, com composição de Noel Rosa e Osvaldo Gogliano.Ver mais em: MARTINHO DA VILA. Feitio de Oração. In: O Pai da Alegria. Brasil: Columbia, 1999.

2 - Versos do hino oficial da ACSESM Camisa Verde e Branco-SP: Sou Verde e Branco, disponível em: http://www.camisaverdebranco.com. Acesso em: 31 mar. 2021.

3 - Trecho da letra da música "Todo menino é um rei", de composição de Roberto Ribeiro, cf. RIBEIRO, Roberto. Todo menino é um rei. In: Sempre. Brasil: Som Livre, 2012.

4 - Referência à Escola de Samba. Pavilhão é a bandeira que traz o símbolo, as cores, o nome e data de fundação da agremiação. 
PAULA, R. C. de; PRADO, P. D.

5 - São locais reservados com relação ao espaço da quadra de modo geral. Com paredes baixas, eles ficam no entorno, não impedindo a visão de toda a quadra localizando-se na parte térrea e superior.

6 - À convite da Coordenadora da Ala a pesquisadora assumiu a função de Apoio da Ala, em janeiro de 2017.

7 - VELOSO, Caetano. Desde que o Samba é Samba. In: Tropicália 2. Rio de Janeiro: Polygram, 1993.

8 - Utiliza-se o termo terreiro compreendendo que este apresenta familiaridade com as culturas negras, aludindo aos terreiros de candomblé e aos terreiros do Samba, como as quadras das Escolas de Samba.

\section{REFERÊNCIAS BIBLIOGRÁFICAS}

BARONETTI, B. S. Transformações na avenida: histórias das escolas de samba da cidade de São Paulo. São Paulo: LiberArs, 2015.

BRITO DA MOTTA, A. B. A atualidade do conceito de gerações na pesquisa sobre o envelhecimento. Sociedade e Estado. Brasília, DF, UnB, v. 25, n. 2, p. 225-250, mai./ago., 2010.

CANAVIEIRA, F. O.; CALDEIRON, A. C. Relações entre crianças pequenas e a produção das culturas infantis: vistas, ouvidas e citadas. In: SILVA, A. et al. Culturas infantis em creches e pré-escolas: estágio e pesquisa. Campinas, SP: Autores Associados, 2011, p. 153-171.

CAVALLEIRO, E. S. Do silêncio do lar ao silêncio escolar: racismo, preconceito e discriminação na Educação Infantil. Dissertação (Mestrado em Educação), Faculdade de Educação, Universidade de São Paulo, São Paulo, 1998.

CRUZ, T. M. CARVALHO, M. P. de. Jogos de gênero: o recreio numa escola de ensino fundamental. Cadernos Pagu. Campinas, SP, Núcleo de Estudos de Gênero, UNICAMP, n. 26, p. 113-143, jan./jun., 2006.

DA MATTA, R. O ofício do etnólogo ou como ter anthropological blues. Boletim do Museu Nacional. Rio de Janeiro, n. 27, p.1-12, 1978.

FARIA, A. L. G.; DEMARTINI, Z. B.; PRADO, P. D. (Orgs.). Por uma cultura da infância: metodologias de pesquisa com crianças. $3^{\mathrm{a}}$ ed., Campinas, SP, Autores Associados, 2009.

FARIAS, A. C. 'Loira você fica muito mais bonita ":relações entre crianças de uma EMEI da cidade de São Paulo e as representações étnico-raciais em seus desenhos. Dissertação (Mestrado em Educação), Faculdade de Educação da Universidade de São Paulo, São Paulo, 2016. 
FERNANDES, F. As "Trocinhas" do Bom Retiro - Contribuição ao estudo folclórico e sociológico da cultura e dos grupos infantis. Pro-Proposições, Campinas, SP, FEUNICAMP, v. 15, n. 1, p. 229-250, jan./abr., 2004. Disponível em: https://periodicos.sbu.unicamp.br/ojs/index.php/proposic/article/view/8643855. Acesso em: 31 mar. 2021.

FERREIRA, M.; NUNES, Â. Estudos da infância, antropologia e etnografia: potencialidades, limites e desafios. Linhas Críticas. Brasília, DF, FE-UnB, v. 20, n. 41, p. 103-123, jan./abr., 2014. Disponível em:

https://periodicos.unb.br/index.php/linhascriticas/article/view/4260. Acesso em: 31 mar. 2021.

FINCO, D. A educação de corpos femininos e masculinos na Educação Infantil. In: FARIA, A. L. G. (Org.). O coletivo infantil em creches e pré-escolas: falares e saberes. São Paulo: Cortez, 2007, p. 94-119.

FINCO, D.. Socialização de Gênero na Educação Infantil. Anais Fazendo Gênero: corpo, violência e poder.UFSC, Florianópolis, SC, p.1-7, 2008. Disponível em:

www.fazendogênero.ufsc.br/8/sts/ST10/Daniela_Finco_10.pdf. Acesso em: 31 mar. 2021. GOMES, N. L. Alguns termos e conceitos presentes no debate sobre relações raciais no Brasil: uma breve discussão. In: BRASIL. Educação Anti-racista: caminhos abertos pela Lei federal no 10.639/03. Brasília, DF, MEC, Secretaria de educação continuada e alfabetização e diversidade, 2005, p. 39-62.

HALL, S. Quem precisa da identidade? In: SILVA, T. T. (Org.). Identidade e diferença: a perspectiva dos estudos culturais. 5a ed., Petrópolis, RJ: Vozes, 2004, p. 103-133.

LARROSA, J. B. Notas sobre a experiência e o saber de experiência. Revista Brasileira de Educação. UNICAMP, Campinas, SP, n. 19, jan./abr., 2002. Disponível em: http://www.scielo.br/pdf/rbedu/n19/n19a02.pdf. Acesso em: 31 mar. 2021.

LUDKE, M.; ANDRÉ, M. A. Pesquisa em educação: abordagens qualitativas. $2^{\text {a }}$ ed., São Paulo: EPU, 2013.

MARCHI, R. C. Pesquisa Etnográfica com Crianças: participação, voz e ética. Educação \& Realidade, Porto Alegre, RS, v.43, n.2, p. 727-746, abr./jun., 2018. Disponível em: http://dx.doi.org/10.15190/2175-623668737. Acesso em: 5 nov. 2021.

MUNANGA, K. Negritude: usos e sentidos. Belo Horizonte, MG: Autêntica, 2009.

NUNES, M. D. F. Mandingas da Infância: as culturas das crianças pequenas na escola municipal Malê Debalê, em Salvador (BA). Tese (Doutorado em Educação), Faculdade de Educação, Universidade de São Paulo, São Paulo, 2017. 
PAULA, R. C. de; PRADO, P. D.

OLIVEIRA, N. Quaesitu. O que é escola de samba? Rio de Janeiro: Imprensa da Cidade, Prefeitura do Rio de Janeiro, 1996.

OLIVEIRA, R. C. O trabalho do antropólogo. Brasília, DF: Paralelo 15; São Paulo: Editora da UNESP, 2000.

OSÓRIO, R. G. A classificação de cor ou raça do IBGE revisitada. In: PETRUCELLI, J. L.; SABÓIA, A. L. (Orgs.). Estudos \& Análises - informação demográfica e socioeconômica: características étnico-raciais da população. Classificações e identidades. Rio de Janeiro: Instituto Brasileiro de Geografia e Estatística, p. 83-99, 2003.

PAULA, R. C. Pura Alegria, acredita que acontece! Infâncias, Identidades Negras e Educação na Escola de Samba Camisa Verde e Branco - SP. Tese (Doutorado em Educação), Faculdade de Educação, Universidade de São Paulo, São Paulo, 2019.

PINHO, V. A.; SANTOS, S. L. Um estudo sobre crianças negras no contexto da educação infantil. Revista da Faculdade de Educação. Cáceres, MT, FE/UNEMAT, v. 22, n. 2, p. 8198, jul./dez., 2014. Disponível em: http://www2.unemat.br/revistafaed/content/vol/vol_22/artigo_22/81_98.pdf. Acesso em: 31 mar. 2021.

PRADO, P. D. As crianças pequeninas produzem cultura? Considerações sobre educação e cultura infantil em creche. Pro-Posições. FE-UNICAMP, Campinas, SP, n.28, p. 110-118, 1999.

PRADO, P. D. Educação Infantil: contrariando as idades. São Paulo, Képos, 2015.

QVORTRUP, J. A infância enquanto categoria estrutural. Educação e Pesquisa. FEUSP, São Paulo, v. 36, n. 2, p. 631-643, mai./ago., 2010. Disponível em: https://www.scielo.br/pdf/ep/v36n2/a14v36n2.pdf. Acesso em: 31 mar. 2021.

ROSEMBERG, F. Relações raciais e rendimento escolar. Cadernos de Pesquisa.São Paulo, Fundação Carlos Chagas, n. 63, p. 19-23, 1987.

SANTIAGO, F. "O meu cabelo é assim... igualzinho o da bruxa, todo armado": hierarquização e racialização das crianças pequenininhas negras na Educação Infantil. Dissertação (Mestrado em Educação), Faculdade de Educação, Universidade Estadual de Campinas, Campinas, SP, 2014.

SAYÃO, D. T. Pequenos homens, pequenas mulheres? Meninos, meninas? Algumas questões para pensar as relações de gênero e infância. Pro-Posições. Campinas, SP, FEUNICAMP, v. 14, n. 3, p. 67-87, set./dez., 2003. Disponível em: https://periodicos.sbu.unicamp.br/ojs/index.php/proposic/article/view/8643862. Acesso em: 31 mar. 2021. 
SCOTT, J. W. Gênero: uma categoria útil de análise histórica. Educação \& Realidade. Porto Alegre, RS, FE/UFRGS, v. 20, n. 2, p. 71-99, 1995. Disponível em:https://seer.ufrgs.br/index.php/educacaoerealidade/article/view/71721. Acesso em: 31 mar. 2021.

SIMSON, O. M. V. Carnaval em branco e negro: Carnaval Popular Paulistano: 1914-1988. Campinas, SP: Editora da UNICAMP; São Paulo: Editora da USP; Imprensa Oficial do Estado de São Paulo, 2007.

SODRÉ, M. Samba, o dono do corpo. Rio de Janeiro: Codecri, 1979.

SOUZA, Y. C. Crianças negras: deixei meu coração embaixo da carteira. Porto Alegre, RS: Mediação, 2002.

SOUZA, M. L. A. "Ser quilombola”: identidade, território e educação na cultura infantil. Tese (Doutorado em Educação), Faculdade de Educação, Universidade Estadual de Campinas, Campinas, SP, 2015.

SOUZA, E. L. Experiências de infâncias com produções de culturas no llê Axé OmoOxélbá Latam. Tese (Doutorado em Educação), Centro de Educação e Ciências Humanas, Universidade Federal de São Carlos, São Carlos, SP, 2016.

Roberta Cristina de Paula: Professora da Educação Básica na Rede Pública Municipal de Campinas/SP (ensino fundamental I). Possui graduação em Pedagogia pela Faculdade de Educação da Universidade Estadual de Campinas (UNICAMP); mestrado em Educação junto ao Departamento de Ciências Sociais e Educação pela FE/UNICAMP; doutorado em Educação pela Faculdade de Educação da Universidade de São Paulo (FEUSP).

Orcid: https://orcid.org/0000-0003-4471-4665

E-mail: rodepaula@hotmail.com

Patrícia Dias Prado: Professora Doutora da Faculdade de Educação da Universidade de São Paulo, FEUSP/SP, junto ao Departamento de Metodologia de Ensino e Educação Comparada - EDM, na área da Infância. Possui graduação em Psicologia pela UNESP, Bauru/SP, mestrado e doutorado em Educação, junto ao Departamento de Ciências Sociais e Educação, da Faculdade de Educação da UNICAMP e Pós-Doutorado em Artes Cênicas, pela Escola de Comunicação e Artes, ECA-USP/SP.

Orcid: https://orcid.org/0000-0002-8790-1594

E-mail: patprado@usp.br

Este periódico utiliza a licença Creative Commons Attribution 3.0, para periódicos de acesso aberto (Open Archives Initiative - OAI). 